Research Paper

\title{
Effect of Lipophilic and Hydrophilic Statins on Breast Cancer Risk in Thai Women: A Cross-sectional Study
}

\author{
Thunyarat Anothaisintawee ${ }^{1}$, Umaporn Udomsubpayakul2, Mark McEvoy ${ }^{3}$, Panuwat Lerdsitthichai ${ }^{4}$, John \\ Attia ${ }^{5}$, Ammarin Thakkinstian ${ }^{6, 凹}$ \\ 1. Department of Family Medicine, Faculty of Medicine, Ramathibodi Hospital, Mahidol University , Bangkok, Thailand \\ 2. Section for Clinical Epidemiology and Biostatistics, Faculty of Medicine, Ramathibodi Hospital, Mahidol University, Bangkok, Thailand \\ 3. Centre for Clinical Epidemiology and Biostatistics, School of Medicine and Public Health, University of Newcastle, NSW, Australia \\ 4. Department of Surgery, Faculty of Medicine, Ramathibodi Hospital, Mahidol University, Bangkok, Thailand \\ 5. Centre for Clinical Epidemiology and Biostatistics, School of Medicine and Public Health, University of Newcastle, and Hunter Medical Research Institute, NSW, \\ Australia \\ 6. Section for Clinical Epidemiology and Biostatistics, Faculty of Medicine, Ramathibodi Hospital, Mahidol University, Bangkok, Thailand \\ $\triangle$ Corresponding author: Ammarin Thakkinstian. Postal address: Section for Clinical Epidemiology and Biostatistics, Ramathibodi Hospital, 270 Rama VI Road, \\ Ratchathevi, Bangkok, Thailand, 10400. Email: ammarin.tha@mahidol.ac.th; Telephone: 662-2011762; Fax: 662-2011284
}

(C) Ivyspring International Publisher. Reproduction is permitted for personal, noncommercial use, provided that the article is in whole, unmodified, and properly cited. See http://ivyspring.com/terms for terms and conditions.

Received: 2016.01.12; Accepted: 2016.04.29; Published: 2016.06.06

\begin{abstract}
Background: Statins are proposed as a chemoprevention agent for breast cancer due to their anti-inflammatory effect. The effects of lipophilic and hydrophilic statins on breast cancer risk might be different due to their different pharmacologic properties. Therefore, this study aimed to assess a casual-effect of lipophilic and hydrophilic statins on breast cancer risk using a counterfactual framework approach.

Methods: A cross-sectional study of 15,718 women who were screened for breast cancer at Mammographic center, Ramathibodi Hospital, Bangkok, Thailand, was conducted during September 2011 to 2012. A counterfactual framework approach was applied to assess causal effects of treatments (i.e., lipophilic and hydrophilic statins) on outcome (i.e. breast cancer). Multi-logit and logistic regression models were used for treatment and outcome models, respectively. An inverse probability weight regression analysis (IPWRA) was then applied to estimate potential outcome mean (POM) and average treatment effect (ATE) by combining the outcome and treatment models.

Results: Breast cancer risks were 0.0072 (95\% Cl: 0.0055, 0.0089), 0.0051 ( $95 \% \mathrm{Cl}$ : 0.0008, 0.0095), and $0.0038(95 \% \mathrm{Cl}: 0.002,0.0056)$ for non-statin users, hydrophilic, and lipophilic statin users, respectively. The estimated risk differences were $-0.0021(95 \% \mathrm{Cl}:-0.0067,0.0026)$ and $-0.0034(95 \%$ $\mathrm{Cl}:-0.0059,-0.0009)$ for hydrophilic and lipophilic statins respectively. The number needed to treat for hydrophilic and lipophilic statins were 2.1 (95\% Cl: $-2.6,6.7)$ and 3.4 (95\% Cl: 1.0, 5.9) per 1000 subjected, respectively.

Conclusions: Our results suggested that using lipophilic statin could significantly reduce risk of breast cancer in Thai women.

Key words: breast neoplasms; hydroxymethylglutaryl-CoA Reductase Inhibitors; hydrophilic statin; lipophilic statin; counterfactual approach
\end{abstract}

\section{Introduction}

Breast cancer is the most common cancer in women across the world. The age standardized incidence rate is 89.2 per 100,000 in the USA [1] and 26.4 per 100,000 in Thailand [2]. Primary prevention of breast cancer is thus very important for decreasing disease burden. Recently, 3-hydroxy-3-methylglu- taryl-coenzyme A reductase (HMG-CoAR) inhibitors (statins) have been proposed as a potential class of chemoprevention agents due to their immunomodulatory and anti-inflammatory effects [3, 4]. By blocking HMG-CoAR, statins can inhibit the mevalonate pathway and reduce cholesterol 
precursors such as farnesyl pyrophosphate (FPP) and geranyl pyrophosphate (GPP) [5]. Depletion of FPP and GPP arrests cell-cycle progression could induce apoptosis, suppress angiogenesis and inhibit tumor growth and metastasis in breast cancer cells [6, 7].

However, clinical evidence for an effect of statin use on breast cancer risk shows inconsistent results, in which some observational studies reported a higher risk of breast cancer in statin users [8-10], whereas others showed protective effects [11-14]. These inconsistent findings might be explained by inadequate sample sizes, different study designs, or analyses, and particularly adjusting for confounding factors in the previous studies.

A meta-analysis that included seven randomized control trials (RCT) was performed to assess the efficacy of statin use in the prevention of breast cancer $[15,16]$. Although their total sample size was very large, they did not detect a treatment effect; this may have been due to high heterogeneity, perhaps explained by pooling studies that used different types of statins (i.e. lipophilic and hydrophilic) together. The effects of lipophilic and hydrophilic statins on breast cancer risk might be different due to their different pharmacologic properties and thus pooling them in one analysis may have obscured a protective effect.

The counterfactual approach has been applied in health science [17-19] and economic [20] research to assess treatment efficacy where RCTs cannot be conducted for ethical reasons or high cost. The approach has become more popular in recent years where electronic records of observational data from routine clinical practice are available. Therefore, this study was conducted to assess the effect of statin types (i.e. lipophilic and hydrophilic) on breast cancer incidence using a counterfactual analysis approach.

\section{Materials and Methods}

\section{Study setting and participants}

The study design was cross-sectional and included 15,718 women, aiming to develop and validate a breast cancer risk prediction model in Thai adult women [21]. This risk prediction model was intended to prioritize women for receiving an organized breast cancer screening program in Thailand. In brief, breast cancer screening data were retrieved from the mammographic center, Ramathibodi Hospital from September 2011 to September 2012. Women with a previous history of invasive breast cancer and ductal carcinoma in situ (DCIS) were excluded.

Self-reported risk factors for breast cancer (i.e. age, family history of breast and ovarian cancers in the first-degree relative, reproductive data (including age at menarche and at first live birth, breastfeeding, and menopausal status), external hormone usage (i.e. hormonal replacement therapy (HRT), oral contraceptives(OC), and medroxyprogesterone injection), history of breast biopsy, body mass index (BMI) , health risk behavior (i.e. smoking and alcohol intake), and underlying diseases (i.e. diabetes mellitus (DM), hypertension, dyslipidemia, and chronic kidney disease (CKD))) were collected by interview. These underlying diseases were also verified with medical databases that contained the 10th revision of the International Statistical Classification of Diseases and Related Health Problems (ICD-10). The ICD-10 were coded by trained hospital staffs.

Details regarding statin usage (i.e. type of statin, and duration of use) were retrieved from the Drug Databases, Medical Statistic Unit, Ramahibodi Hospital. These data were then merged with mammographic screening data. Statins were classified as hydrophilic (i.e., pravastatin and rosuvastatin) or lipophilic (i.e., atorvastatin, simvastatin, pitavastatin, and fluvastatin) [22]. Statin use was defined as using any types of statin for at least 6 months.

The primary outcomes of interest were combined invasive breast cancer and DCIS, which were verified by pathological diagnosis. This study was approved by the Institutional Review Board of Ramathibodi Hospital, Mahidol University and complied with the principles of Declaration of Helsinki. All participants provided written inform consent.

\section{Statistical analysis}

Characteristics of subjects were described by lipophilic and hydrophilic statin user and non-user groups using frequency (\%) and mean if they were categorical and continuous data, respectively. These characteristics were compared using Chi-square and t-tests, respectively. Treatment effect of statins was determined using a counterfactual analysis [23, 24]. Two equations were simultaneously constructed as follows: First, the treatment model was constructed by fitting treatment variable (i.e., hydrophilic statin vs lipophilic statin vs non-statin using) on covariates (i.e. age, BMI, DM, hypertension, CKD, age at menarche and menopause, smoking, alcohol drinking, OC and HRT use) using multi-logit equation. Probabilities of receiving and not receiving treatments were then estimated. Second, the outcome model was constructed using a logit equation by fitting the breast cancer variable on the covariates (i.e. age, family history of breast and ovarian cancers in the first-degree relative, age at menarche and at first live birth, breastfeeding, menopausal status, HRT, OC), and medroxyprogesterone injection use, history of 
breast biopsy, BMI, smoking, alcohol intake, DM, hypertension, dyslipidemia, and CKD).

An inverse probability weight regression analysis (IPWRA) was then applied to estimate potential outcome mean (POM) and average treatment effect (ATE) by combining the outcome and treatment models. An overlap assumption (i.e., each individual woman had a positive probability of receiving each treatment) was assessed using an overlap plot. The plot displayed estimated densities of predicted probability of each treatment level after adjusting for covariates. The overlap assumption is not violated if there is a chance of seeing patients in both treatment and control groups for each combination of covariates. STATA version 14.0 was used for the analyses [25]. P value less than 0.05 was considered as statistically significant.

Table 1. Characteristics between lipophilic, hydrophilic statin users and non-statin users

\begin{tabular}{|c|c|c|c|c|}
\hline \multirow[t]{2}{*}{ Characteristics } & \multicolumn{2}{|l|}{ Statin users } & \multirow{2}{*}{$\begin{array}{l}\text { Non-users }(\%) \\
(n=9,703)\end{array}$} & \multirow[t]{2}{*}{ P-value } \\
\hline & $\begin{array}{l}\text { Lipophilic (\%) } \\
(\mathrm{n}=4,624)\end{array}$ & $\begin{array}{l}\text { Hydrophilic (\%) } \\
(\mathrm{n}=1,391)\end{array}$ & & \\
\hline \multicolumn{4}{|l|}{ Age, years } & \multirow[t]{4}{*}{$<0.001$} \\
\hline$\leq 50$ & $490(10.60)$ & $140(7.48)$ & $4,225(43.54)$ & \\
\hline $51-60$ & $2,206(47.71)$ & $755(54.28)$ & $3,946(40.67)$ & \\
\hline$>60$ & $1,928(41.70)$ & $532(38.25)$ & 1,532 (15.79) & \\
\hline \multicolumn{5}{|l|}{ BMI, $\mathrm{kg} / \mathrm{m}^{2}$} \\
\hline$<23$ & $1,624(35.17)$ & $525(37.74)$ & 4,994 (51.50) & \multirow[t]{3}{*}{$<0.001$} \\
\hline $23-26$ & $1,584(34.30)$ & $508(36.52)$ & $2,701(27.85)$ & \\
\hline$>26$ & $1,410(30.53)$ & $358(25.74)$ & $2,002(20.65)$ & \\
\hline \multicolumn{5}{|l|}{ Smoking } \\
\hline No & 4,591(99.35) & $1,382(99.50)$ & 9,625 (99.31) & \multirow[t]{2}{*}{0.701} \\
\hline Yes & $30(0.65)$ & $7(0.50)$ & $67(0.69)$ & \\
\hline \multicolumn{5}{|c|}{ Alcohol drinking } \\
\hline No & 3,997 (86.44) & $1,183(85.05)$ & $8,186(84.37)$ & \multirow[t]{2}{*}{0.005} \\
\hline Yes & $627(13.56)$ & 208 (14.95) & $1,517(15.63)$ & \\
\hline \multicolumn{5}{|l|}{ Hypertension } \\
\hline No & 2,292 (49.57) & $866(62.26)$ & 7703 (79.39) & \multirow[t]{2}{*}{$<0.001$} \\
\hline Yes & $2,332(50.43)$ & $525(37.74)$ & $2000(20.61)$ & \\
\hline \multicolumn{5}{|c|}{ Diabetes mellitus } \\
\hline No & $3,839(83.02)$ & 1,249 (89.79) & 9252 (95.35) & \multirow[t]{2}{*}{$<0.001$} \\
\hline Yes & 785 (16.98) & $142(10.21)$ & $451(4.65)$ & \\
\hline \multicolumn{5}{|c|}{ Chronic kidney disease } \\
\hline No & $4,479(96.86)$ & $1,369(98.42)$ & 9603 (98.97) & \multirow[t]{2}{*}{$<0.001$} \\
\hline Yes & $145(3.14)$ & $22(1.58)$ & $100(1.03)$ & \\
\hline \multicolumn{5}{|c|}{ Oral contraceptive use } \\
\hline Never & $3,354(72.53)$ & $1,010(72.61)$ & $6971(71.84)$ & \multirow[t]{3}{*}{$<0.001$} \\
\hline Ex-users & $1,252(27.08)$ & $374(26.89)$ & $2494(25.70)$ & \\
\hline Current users & $18(0.39)$ & $7(0.50)$ & $238(2.45)$ & \\
\hline \multicolumn{5}{|l|}{ HRT use } \\
\hline Never & $3,518(76.48)$ & 992 (71.73) & 8467 (87.61) & \multirow[t]{3}{*}{$<0.001$} \\
\hline Ex-users & $898(19.52)$ & $341(24.66)$ & $913(9.45)$ & \\
\hline Current users & $184(4.00)$ & $50(3.62)$ & $284(2.94)$ & \\
\hline
\end{tabular}

aFrom chi-square test

BMI: body mass index; HRT: hormonal replacement therapy

\section{Results}

Among 15,718 participants, 107 women were diagnosed with breast cancer with a prevalence of $0.68 \%$ (95\% CI: $0.56 \%, 0.82 \%)$. A total of 6,015 (38.3\%) women were statin users with a mean duration of use of $7.27(\mathrm{SD}=1.21)$ years. Among statin users, 4624 $(77 \%)$ women were prescribed a lipophilic statin, whereas 1,391(23\%) women were prescribed a hydrophilic statin.

Characteristics between lipophilic and hydrophilic statin user and non-user groups are presented in Table 1. The distributions of 8 variables (i.e. age, BMI, alcohol drinking, history of hypertension, DM, and CKD, OC and HRT uses,) were significantly different between lipophilic and hydrophilic statin users and non-statin users (see Table 1). However, results from the multivariate multi-logit model showed only age, BMI, history of hypertension, DM, and CKD, and HRT use were statistically significantly associated with lipophilic and hydrophilic statin uses (see Table 2), and these variables were further considered in the treatment model.

Table 2. Factors associated with statin use: A multivariate multi-logit model

\begin{tabular}{|c|c|c|c|c|}
\hline Factors & Coefficient & $\begin{array}{l}\text { Standard } \\
\text { error }\end{array}$ & P-value & Odds ratio $(95 \% \mathrm{CI})$ \\
\hline \multicolumn{5}{|c|}{ Lipophilic statin } \\
\hline \multicolumn{5}{|c|}{ Age, years } \\
\hline$\leq 50$ & - & - & - & 1 \\
\hline $51-60$ & 1.37 & 0.057 & $<0.001$ & $3.93(3.52,4.39)$ \\
\hline$>60$ & 1.95 & 0.063 & $<0.001$ & $7.04(6.22,7.97)$ \\
\hline \multicolumn{5}{|l|}{ BMI, $\mathrm{kg} / \mathrm{m}^{2}$} \\
\hline$<23$ & - & - & - & 1 \\
\hline $23-26$ & 0.35 & 0.047 & $<0.001$ & $1.42(1.29,1.55)$ \\
\hline$>26$ & 0.38 & 0.051 & $<0.001$ & $1.46(1.32,1.62)$ \\
\hline \multicolumn{5}{|l|}{ Hypertension } \\
\hline No & - & - & - & 1 \\
\hline Yes & 0.77 & 0.044 & $<0.001$ & $2.15(1.97,2.34)$ \\
\hline \multicolumn{5}{|c|}{ Diabetes mellitus } \\
\hline No & - & - & - & 1 \\
\hline Yes & 0.81 & 0.069 & $<0.001$ & $2.26(1.97,2.59)$ \\
\hline \multicolumn{5}{|c|}{ Chronic kidney disease } \\
\hline No & - & - & - & 1 \\
\hline Yes & 0.99 & 0.150 & $<0.001$ & $2.70(2.01,3.62)$ \\
\hline \multicolumn{5}{|l|}{ HRT use } \\
\hline Never & - & - & - & 1 \\
\hline Ex-users & 0.35 & 0.056 & $<0.001$ & $1.42(1.27,1.59)$ \\
\hline Current users & 0.53 & 0.106 & $<0.001$ & $1.70(1.38,2.09)$ \\
\hline \multicolumn{5}{|c|}{ Hydrophilic statin } \\
\hline \multicolumn{5}{|l|}{ Age, years } \\
\hline$\leq 50$ & - & - & - & 1 \\
\hline $51-60$ & 1.89 & 0.109 & $<0.001$ & $6.64(5.37,8.22)$ \\
\hline$>60$ & 2.33 & 0.116 & $<0.001$ & $10.27(8.17,12.89)$ \\
\hline \multicolumn{5}{|l|}{ BMI, $\mathrm{kg} / \mathrm{m}^{2}$} \\
\hline$<23$ & - & - & - & 1 \\
\hline $23-26$ & 0.40 & 0.070 & $<0.001$ & $1.49(1.30,1.71)$ \\
\hline$>26$ & 0.32 & 0.079 & $<0.001$ & $1.38(1.18,1.61)$ \\
\hline \multicolumn{5}{|l|}{ Hypertension } \\
\hline No & - & - & - & 1 \\
\hline Yes & 0.32 & 0.067 & $<0.001$ & $1.37(1.20,1.56)$ \\
\hline \multicolumn{5}{|c|}{ Diabetes mellitus } \\
\hline No & - & - & - & 1 \\
\hline Yes & 0.42 & 0.107 & $<0.001$ & $1.52(1.23,1.88)$ \\
\hline \multicolumn{5}{|c|}{ Chronic kidney disease } \\
\hline No & - & - & - & 1 \\
\hline Yes & 0.43 & 0.252 & 0.090 & $1.53(0.94,2.52)$ \\
\hline \multicolumn{5}{|l|}{ HRT use } \\
\hline Never & - & - & - & 1 \\
\hline Ex-users & 0.63 & 0.075 & $<0.001$ & $1.88(1.62,2.18)$ \\
\hline Current users & 0.42 & 0.162 & 0.010 & $1.52(1.10,2.09)$ \\
\hline
\end{tabular}

BMI: body mass index; CI: confidence interval; HRT: hormonal replacement therapy 
Table 3. Characteristics between breast cancer and non-breast cancer women

\begin{tabular}{|c|c|c|c|}
\hline Characteristics & $\begin{array}{l}\text { Breast cancers } \\
\mathrm{n}=107(\%)\end{array}$ & $\begin{array}{l}\text { Non-breast cancers } \\
\mathrm{n}=15,611(\%)\end{array}$ & P-value \\
\hline \multicolumn{4}{|c|}{ Demographic data } \\
\hline \multicolumn{4}{|l|}{ Age, year } \\
\hline$\leq 60$ & $76(71.03)$ & $11,650(74.63)$ & 0.395 \\
\hline$>60$ & $31(28.97)$ & $3,961(25.37)$ & \\
\hline \multicolumn{4}{|l|}{$\mathrm{BMI}, \mathrm{kg} / \mathrm{m}^{2}$} \\
\hline$\leq 23$ & $36(33.64)$ & $7,110(45.54)$ & 0.020 \\
\hline $24-26$ & $35(32.71)$ & $4,764(30.52)$ & \\
\hline$\geq 27$ & $36(33.64)$ & $3,737(23.94)$ & \\
\hline \multicolumn{4}{|c|}{ History of smoking } \\
\hline Never & $106(99.07)$ & $15,508(99.34)$ & 0.730 \\
\hline Ever & $1(0.93)$ & $103(0.66)$ & \\
\hline \multicolumn{4}{|c|}{ History of alcohol drinking } \\
\hline Never & $94(87.85)$ & $13,272(85.11)$ & \\
\hline Ever & $13(12.15)$ & 2,322 (14.89) & 0.428 \\
\hline \multicolumn{4}{|c|}{ Family history of cancer in $1^{\text {st }}$ degree relative } \\
\hline \multicolumn{4}{|c|}{ Breast cancer } \\
\hline No & $103(96.26)$ & $14,249(91.40)$ & 0.083 \\
\hline Yes & $4(3.74)$ & $1,341(8.6)$ & \\
\hline \multicolumn{4}{|l|}{ Ovarian cancer } \\
\hline No & $104(99.05)$ & $15,442(99.16)$ & 0.915 \\
\hline Yes & $1(0.95)$ & $131(0.84)$ & \\
\hline \multicolumn{4}{|c|}{ Underlying diseases } \\
\hline \multicolumn{4}{|c|}{ Diabetes mellitus } \\
\hline Yes & $15(14.02)$ & $1,363(8.73)$ & 0.06 \\
\hline No & $92(85.98)$ & $14,248(91.27)$ & \\
\hline \multicolumn{4}{|c|}{ Chronic kidney disease } \\
\hline Yes & $4(3.74)$ & $233(1.49)$ & 0.067 \\
\hline No & $103(96.26)$ & $15,378(98.51)$ & \\
\hline \multicolumn{4}{|l|}{ Dyslipidemia } \\
\hline Yes & $14(13.08)$ & 2,896 (18.59) & 0.048 \\
\hline No & $67(62.62)$ & $8,269(52.97)$ & \\
\hline \multicolumn{4}{|c|}{ Reproductive history } \\
\hline \multicolumn{4}{|c|}{ Age at menarche, year } \\
\hline$\leq 13$ & $39(36.45)$ & $6,492(41.59)$ & 0.325 \\
\hline$>13$ & $68(63.55)$ & $9,119(58.41)$ & \\
\hline \multicolumn{4}{|c|}{ Age at first live birth, year } \\
\hline Nulliparity & 31 (28.97) & $5,394(34.55)$ & 0.477 \\
\hline$\leq 29$ & $51(47.66)$ & $6,772(43.38)$ & \\
\hline$>29$ & $25(23.36)$ & $3,445(22.07)$ & \\
\hline \multicolumn{4}{|c|}{$\begin{array}{l}\text { Duration of Breastfeeding, } \\
\text { month }\end{array}$} \\
\hline Never & $41(38.32)$ & $7,198(46.11)$ & 0.119 \\
\hline $1-6$ & $31(28.97)$ & $4,645(29.75)$ & \\
\hline$\geq 6$ & $35(32.71)$ & $3,768(24.14)$ & \\
\hline \multicolumn{4}{|c|}{ Menopausal status } \\
\hline postmenopausal & $62(57.94)$ & $10,893(69.78)$ & 0.009 \\
\hline premenopausal & $45(42.06)$ & $4,718(30.22)$ & \\
\hline History of breast & & & \\
\hline Yes & $14(13.08)$ & 2,896 (18.59) & 0.147 \\
\hline No & $93(86.92)$ & $12,686(81.41)$ & \\
\hline History of HRT & & & \\
\hline Never & $100(93.46)$ & $12,934(82.85)$ & 0.028 \\
\hline Past user & $6(5.61)$ & 2,156 (13.81) & \\
\hline Current user & $1(0.93)$ & $521(3.34)$ & \\
\hline History of OC us & & & \\
\hline Never & $68(63.55)$ & 11267 (72.17) & $<0.001$ \\
\hline Past user & $30(28.04)$ & $4,090(26.20)$ & \\
\hline Current user & $9(8.41)$ & $254(1.63)$ & \\
\hline History of medrc & njection use & & \\
\hline Never & 98 (91.59) & $14,632(93.73)$ & 0.366 \\
\hline Ever use & $9(8.41)$ & $979(6.27)$ & \\
\hline
\end{tabular}

BMI: body mass index; HRT: hormonal replacement therapy; OC: oral contraceptive
Characteristics of subjects between breast cancer and non-breast cancer groups are summarized in Table 3. A simple logistic regression suggested 11 variables (i.e. age, BMI, family history of breast cancer, CKD, DM, DLP, duration of breastfeeding, menopausal status, history of breast biopsy, OC and HRT usages) that were considered in multiple logistic regression model. However, only 4 variables (i.e. age, BMI, OC, and menopausal status) were significantly associated with breast cancer and then were kept in the outcome model (see Table 4).

Table 4. Factors associated with breast cancer and the scoring scheme from multivariate logistic regression analysis

\begin{tabular}{|c|c|c|c|c|}
\hline Factors & Coefficient & SE & $P$ value & OR $(95 \% \mathrm{CI})$ \\
\hline \multicolumn{5}{|l|}{ Age, year } \\
\hline$>60$ & 0.54 & 0.25 & 0.035 & $1.71(1.04,2.81)$ \\
\hline$\leq 60$ & & & & 1 \\
\hline \multicolumn{5}{|c|}{ Oral contraceptive use } \\
\hline Current user & 1.52 & 0.38 & $<0.001$ & $4.58(2.16,9.71)$ \\
\hline Past user & 0.16 & 0.22 & 0.473 & $1.17(0.76,1.80)$ \\
\hline Never user & & & & 1 \\
\hline \multicolumn{5}{|l|}{ BMI, $\mathrm{kg} / \mathrm{m}^{2}$} \\
\hline$\geq 27$ & 0.70 & 0.24 & 0.003 & $2.02(1.26,3.24)$ \\
\hline $24-26$ & 0.44 & 0.24 & 0.070 & $1.55(0.97,2.49)$ \\
\hline$\leq 23$ & & & & 1 \\
\hline \multicolumn{5}{|c|}{ Menopausal status } \\
\hline Premenopause & 0.64 & 0.24 & 0.008 & $1.91(1.18,3.08)$ \\
\hline Postmenopause & & & & 1 \\
\hline
\end{tabular}

\section{Risk of breast cancer and statin use}

The POMs (i.e., breast cancer risks) estimated using the IPWRA method were 0.0072 (95\% CI: 0.0055, $0.0089), 0.0051$ (95\% CI: $0.0008,0.0095)$, and 0.0038 (95\% CI: 0.002, 0.0056) for non-statin users, hydrophilic, and lipophilic statin users, respectively, see Table 5. The estimated ATEs (i.e., risk differences) were -0.0021 (95\% CI: $-0.0067,0.0026)$ and -0.0034 (95\% CI: -0.0059, -0.0009) for hydrophilic and lipophilic statins, respectively. The number needed to treat for these corresponding statins were 2.1 (95\% CI: -2.6, 6.7) and $3.4(95 \%$ CI: $1.0,5.9)$ per 1000 subjects, i.e., we could prevent breast cancer in about 2 and 3 subjects for every 1000 subjects treated with hydrophilic and lipophilic statins respectively, although only the lipophilic statin is statistically significant.

Table 5. Statin-treatment effect model on breast cancer risk

\begin{tabular}{llllll}
\hline Model & Factors & \multicolumn{2}{l}{$\begin{array}{l}\text { Risk } \\
\text { difference }\end{array}$} & SE & \multicolumn{2}{l}{ P-value } & 95\% CI \\
\hline ATE & $\begin{array}{l}\text { Lipophilic statin users vs } \\
\text { non-users }\end{array}$ & -0.0034 & 0.001 & 0.008 & -0.006, \\
& $\begin{array}{lllll}\text { Hydrophilic statin users vs } \\
\text { non-users }\end{array}$ & -0.0021 & 0.002 & 0.381 & -0.001 \\
POM & Factors & Risk & SE & P-value & 95\% CI \\
& Non-statin users & 0.0072 & 0.001 & $<0.001$ & $0.006,0.009$ \\
& Lipophilic statin users & 0.0038 & 0.001 & $<0.001$ & $0.002,0.006$ \\
& Hydrophilic statin users & 0.0051 & 0.002 & 0.019 & $0.001,0.010$ \\
\hline ATE: average treatment effect; CI: confidence interval; POM: potential outcome \\
mean; SE: standard error
\end{tabular}


The overlap assumption for applying the treatment effect model was checked by plotting estimated densities of predicted probability (i.e., that non-statin users were non-statin users, and predicted probabilities that statin-users were non-statin users) against propensity score, see Figure S1. The overlap assumption is violated if there is evidence that the estimated density has too much mass around 0 and 1 . The plot indicated that the predicted probability that non-statin users were actually not assigned to statin (either lipophilic- or hydrophilic-statin) and predicted probability that statin-users were non-statin users mostly overlapped, although the predicted probability that non-statin users would not be assigned to treatment (either lipophilic- or hydrophilic-statin) had some of its mass around 0.8 to 0.9. Thus, the overlap assumption was largely observed.

\section{Discussion}

We assessed the effect of statin use on lowering breast cancer risk using a counterfactual analysis approach. Our results showed that using lipophilic statins but not hydrophilic statins could significantly reduce risk of breast cancer in Thai women. For every 1000 women treated with a lipophilic statin, 3 women would avoid breast cancer.

Our findings correspond with some previous studies that reported a significantly decreased risk of breast cancer in statin users. Cauley et al. found that among women aged 65 years or older, statin use significantly reduced risk of breast cancer with a hazard ratio of 0.28 (95\% CI: 0.09, 0.86) [11]. Moreover, results from a retrospective cohort study showed a reduced breast cancer risk in women who had used statins for longer than 4 years (odds ratio $=0.26,95 \%$ CI: $0.12,0.55)$ [8]. The protective effect of statins on breast cancer risk can potentially be explained through the statins' inhibition of the mevalonate pathway. This inhibition disrupts cancer cell growth, and leads to apoptotic cell death [5-7]. In addition, statins impede the activation of the proteasome pathway, and prevent the breakdown of p21 and p27. These molecules can accelerate growth-inhibitory effects and retard cancer cell mitosis [26, 27].

Lipophilic statins can penetrate the cell plasma membrane, whilst hydrophilic statins cannot [28]. Cellular penetration of lipophilic statins may be associated with their inhibition of cell growth. This hypothesis is supported by the findings from a cell culture study in which lipophilic statins but not hydrophilic statins had anticancer action [29]. These observations are consistent with the results from our study that using lipophilic statins significantly reduced the risk of breast cancer by around $48 \%$, whereas hydrophilic statins were not significantly associated with breast cancer risk, although the point estimate suggests a smaller risk reduction of $29 \%$. Moreover, results from the Women's Health Initiative Study showed that lipophilic statin use was associated with an $18 \%$ lower breast cancer risk ( $\mathrm{HR}=0.82,95 \%$ $\mathrm{CI}=0.70,0.97$ [ [30]., although the updated results failed to confirm this association [31]. This conflicting result may be due to misclassification of types of statins in the updated findings, in which atorvastatin was classified as hydrophilic instead of lipophilic.

However, our results contrast with the findings from two meta-analyses that did not find any protective effects of statin use on breast cancer risk. The meta-analysis of observational studies showed no association (pooled $\mathrm{RR}=0.99,95 \% \mathrm{CI}=0.94,1.04$ ) [16], whereas a meta-analysis of RCT suggested a risk effect of statin use (pooled RR $=1.19 ; 95 \% \mathrm{CI}, 0.81$ to 1.73) [15]. The meta-analysis of observational studies included studies with different study designs, types and durations of statin use. Pooling statin effects was mainly based on crude effects, thus the pooled effect is prone for confounding bias. The meta-analysis of RCTs included studies that were primarily designed to assess the effect of statins on other disease conditions, not breast cancer, and so, risk factors for cancer and cancer endpoints were not systematically collected. Therefore, surveillance bias may be a problem.

Our study had some strengths. We made use of routinely available clinical data combine with survey data that we had collected in the mammography clinic. Thus, all possible risk factors for breast cancer were collected and considered in the counterfactual analysis. All women were screened with mammography and breast cancer cases were verified with pathological diagnosis. Thus, surveillance and detection bias were less likely to occur in our study. We estimated the statin treatment effects using counterfactual analysis, which allowed us to estimate what the incidence would be if non-statin users received treatment or vice versa. On the other hand, our data on statin use were retrieved from a drug database, with no objective measure of actual drug compliance; however this would probably have biased us towards the null (people over-report compliance) rather than away from the null.

In conclusion, use of lipophilic statin might reduce the risk of breast cancer in Thai women.

\section{Supplementary Material}

Figure S1. http:/ / www.jcancer.org/v07p1163s1.pdf 


\section{Competing Interests}

The authors have declared that no competing interest exists.

\section{References}

1. Ferlay J, Bray F, Steliarova-Foucher E, D F. CI5 I-X: cancer incidence in five continents, volumes I to X. Lyon, France: IARC Press; 2014.

2. Khuhaprema T, Attasara P, Sriplung H, Wiangnon S, Sangrajrang S. Cancer Incidence in Thailand. In: Khuhaprema T, editor. Cancer in Thailand Volume VII, 2007-2009. Bangkok, Thailand: National Cancer Institute; 2013:p 46.

3. Jain MK, Ridker PM. Anti-inflammatory effects of statins: clinical evidence and basic mechanisms. Nature reviews Drug discovery. 2005; 4: 977-87.

4. Kwak B, Mulhaupt F, Myit S, Mach F. Statins as a newly recognized type of immunomodulator. Nature medicine. 2000; 6: 1399-402.

5. Kang S, Kim ES, Moon A. Simvastatin and lovastatin inhibit breast cell invasion induced by H-Ras. Oncology reports. 2009; 21: 1317-22.

6. Laezza C, Malfitano AM, Proto MC, Esposito I, Gazzerro P, Formisano P, et al. Inhibition of 3-hydroxy-3-methylglutaryl-coenzyme A reductase activity and of Ras farnesylation mediate antitumor effects of anandamide in human breast cancer cells. Endocrine-related cancer. 2010; 17: 495-503.

7. Thurnher M, Nussbaumer O, Gruenbacher G. Novel aspects of mevalonate pathway inhibitors as antitumor agents. Clinical cancer research : an official journal of the American Association for Cancer Research. 2012; 18: 3524-31.

8. Beck P, Wysowski DK, Downey W, Butler-Jones D. Statin use and the risk of breast cancer. Journal of clinical epidemiology. 2003; 56: 280-5.

9. Eaton M, Eklof J, Beal JR, Sahmoun AE. Statins and breast cancer in postmenopausal women without hormone therapy. Anticancer research. 2009; 29: 5143-8.

10. Coogan PF, Rosenberg L, Palmer JR, Strom BL, Zauber AG, Shapiro S. Statin use and the risk of breast and prostate cancer. Epidemiology (Cambridge, Mass). 2002; 13: 262-7.

11. Cauley JA, Zmuda JM, Lui LY, Hillier TA, Ness RB, Stone KL, et al. Lipid-lowering drug use and breast cancer in older women: a prospective study. Journal of women's health (2002). 2003; 12: 749-56.

12. Cauley JA, McTiernan A, Rodabough RJ, LaCroix A, Bauer DC, Margolis KL, et al. Statin use and breast cancer: prospective results from the Women's Health Initiative. Journal of the National Cancer Institute. 2006; 98: 700-7.

13. Pocobelli G, Newcomb PA, Trentham-Dietz A, Titus-Ernstoff L, Hampton JM, Egan KM. Statin use and risk of breast cancer. Cancer. 2008; 112: 27-33.

14. Haukka J, Sankila R, Klaukka T, Lonnqvist J, Niskanen L, Tanskanen A, et al. Incidence of cancer and statin usage--record linkage study. International journal of cancer Journal international du cancer. 2010; 126: 279-84.

15. Bonovas S, Filioussi K, Tsavaris N, Sitaras NM. Use of statins and breast cancer: a meta-analysis of seven randomized clinical trials and nine observational studies. J Clin Oncol. 2005; 23: 8606-12.

16. Undela K, Srikanth V, Bansal D. Statin use and risk of breast cancer: a meta-analysis of observational studies. Breast Cancer Res Treat. 2012; 135: 261-9.

17. Tararbit K, Lelong N, Houyel L, Bonnet D, Goffinet F, Khoshnood B. Assessing the role of multiple pregnancies in the association between tetralogy of Fallot and assisted reproductive techniques: a path-analysis approach. Orphanet Journal of Rare Diseases. 2014; 9: 27-.

18. McDonald S, Lambert J. The Long Arm of Mentoring: A Counterfactual Analysis of Natural Youth Mentoring and Employment Outcomes in Early Careers. Am J Community Psychol. 2014; 54: 262-73.

19. Luo Z, Gardiner JC, Bradley CJ. Applying Propensity Score Methods in Medical Research: Pitfalls and Prospects. Medical Care Research and Review. 2010; 67: 528-54.

20. Schofield DJ, Callander EJ, Shrestha RN, Passey ME, Kelly SJ, Percival R. Multiple chronic health conditions and their link with wealth assets. Eur J Public Health. 2015; 25: 285-9.

21. Anothaisintawee $\mathrm{T}$, Teerawattananon $\mathrm{Y}$, Wiratkapun $\mathrm{C}$, Srinakarin J, Woodtichartpreecha P, Hirunpat S, et al. Development and validation of a breast cancer risk prediction model for Thai women: a cross-sectional study. Asian Pacific journal of cancer prevention : APJCP. 2014; 15: 6811-7.

22. Schachter M. Chemical, pharmacokinetic and pharmacodynamic properties of statins: an update. Fundamental \& clinical pharmacology. 2005; 19: 117-25.

23. Cerulli G. ivtreatreg: A command for fitting binary treatment models with heterogeneous response to treatment and unobservable selection. Stata Journal. 2014; 14: 453-80.

24. Cerulli G. treatrew: A user-written command for estimating average treatment effects by reweighting on the propensity score. Stata Journal. 2014; 14: 541-61.

25. StataCorp. Stata Statistical Software: Release 14. . Treatment-Effects Reference Manual. College Station, TX: StataCorp LP; 2014.

26. Denoyelle $C$, Vasse $M$, Korner $M$, Mishal Z Ganne $F$, Vannier JP, et al. Cerivastatin, an inhibitor of HMG-CoA reductase, inhibits the signaling pathways involved in the invasiveness and metastatic properties of highly invasive breast cancer cell lines: an in vitro study. Carcinogenesis. 2001; 22: 1139-48.

27. Shibata MA, Kavanaugh C, Shibata E, Abe H, Nguyen P, Otsuki Y, et al. Comparative effects of lovastatin on mammary and prostate oncogenesis in transgenic mouse models. Carcinogenesis. 2003; 24: 453-9.
28. Davidson MH. Rosuvastatin: a highly efficacious statin for the treatment of dyslipidaemia. Expert opinion on investigational drugs. 2002; 11: 125-41.

29. Campbell MJ, Esserman LJ, Zhou Y, Shoemaker M, Lobo M, Borman E, et al. Breast Cancer Growth Prevention by Statins. Cancer Research. 2006; 66: 8707-14.

30. Cauley JA, McTiernan A, Rodabough RJ, LaCroix A, Bauer DC, Margolis KL, et al. Statin Use and Breast Cancer: Prospective Results From the Women's Health Initiative. Journal of the National Cancer Institute. 2006; 98: 700-7.

31. Desai P, Chlebowski R, Cauley JA, Manson JE, Wu C, Martin LW, et al. Prospective Analysis of Association between Statin Use and Breast Cancer Risk in the Women's Health Initiative. Cancer Epidemiology Biomarkers \& Prevention. 2013; 22: 1868-76. 